\title{
The Effects of Ketamine and Its Enantiomers on the Morphine- or Dexmedetomidine-induced Antinociception after Intratbecal Administration in Rats
}

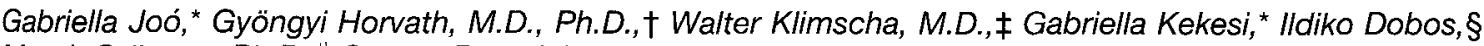
Margit Szikszay, Ph.D.,|| György Benedek, M.D., D.Sc.\#

\begin{abstract}
Background: The spinal administration of some N-methyl-Daspartate receptor antagonists results in antinociception and potentiates the effects of opioids and $\alpha_{2}$-adrenoceptor agonists, but ketamine and its enantiomers have not been examined. The present study investigated the interactions of racemic ketamine, $R(-)$-ketamine and $s(+)$-ketamine with morphine and with dexmedetomidine.

Metbods: Intrathecal catheters were implanted into male Wistar rats. Three days later, the acute nociceptive sensitivity was assessed using the tail-flick test. Analgesic latencies were converted to the percentage maximum possible effect. The dose that yielded $50 \%$ of the maximum possible effect $\left(E D_{50}\right)$ and dose-response and time-course curves were determined for the ketamines $(30-300 \mu \mathrm{g})$, morphine $(0.1-3.0 \mu \mathrm{g})$, dexmedetomidine $(0.3-10.0 \mu \mathrm{g})$, and mixtures of two doses of ketamines
\end{abstract}

*Ph.D. Student, Department of Physiology, Albert Szent-Györgyi Medical University.

t Professor, Department of Physiology and Faculty of Health Science, Albert Szent-Györgyi Medical University.

\# Associate Professor, Department of Anesthesiology and Intensive Care, University of Vienna, Austria.

$\$$ Technical Assistant, Department of Physiology, Albert Szent-Györgyi Medical University.

|| Associate Professor, Department of Physiology, Albert Szent-Györgyi Medical University.

* Chairman and Professor of Physiology, Department of Physiology, Albert Szent-Györgyi Medical University.

Received from the Department of Physiology, Albert Szent-Györgyi Medical University, Szeged, Hungary. Submitted for publication July 19, 1999. Accepted for publication March 15, 2000. Supported by grant No. ETT T-03 590/96 from the Hungarian Health Science Committe Budapest, Budapest, Hungary; grant No. OTKA T-029817 from the Hungarian Science Foundation, Budapest, Hungary; and grant No. 247/3/7197 from the Soros Foundation, Budapest, Hungary. Presented in part at the congress of the Hungarian Neroscience Society, Harkány, Hungary, January 28-30,1999, and the Second European Congress of Pharmacology (EPHAR '99), Budapest, Hungary, July 3-7, 1999.

Address reprint requests to Dr. Horvath: Department of Physiology, Albert Szent-Györgyi Medical University, P.O. Box 427, H-6701, Szeged, Hungary. Address electronic mail to: horvath@phys.szote.u-szeged.hu
(30 or $100 \mu \mathrm{g}$ ) with different doses of morphine or dexmedetomidine for fixed-dose analysis.

Results: Neither racemic ketamine nor its enantiomers alone had a significant effect on the tail-flick test, with the exception of the highest dose of racemic ketamine, which caused motor impairment. Morphine and dexmedetomidine each produced dose-dependent antinociception, with $\mathrm{ED}_{50}$ of $1.7 \mu \mathrm{g}(95 \%$ confidence interval: 1.04-2.32) and $4.85 \mu \mathrm{g}$ (3.96-5.79), respectively. A low dose $(30 \mu \mathrm{g})$ of racemic ketamine or its enantiomers did not influence the $\mathrm{ED}_{50}$ of morphine significantly. Coadministration of $100 \mu \mathrm{g}$ racemic ketamine or $S(+)$-ketamine, but not $R(-)$-ketamine, significantly enhanced and prolonged the antinociceptive effect of morphine. Both doses of racemic ketamine or its isomers significantly decreased the $\mathrm{ED}_{50}$ value for dexmedetomidine, although the higher dose of racemic or $S(+)$-ketamine had the highest potency. One-hundred micrograms of racemic ketamine or $s(+)$-ketamine also prolonged the effects of dexmedetomidine.

Conclusions: These data indicate that racemic ketamine and $S(+)$-ketamine, but not $R(-)$-ketamine, exhibit similar effectiveness in potentiating the antinociceptive effects of both morphine and dexmedetomidine. (Key words: Adrenoceptor; NMDA antagonist; opioid; pain; spinal.)

NUMEROUS studies performed at the level of the spinal cord have shown that $N$-methyl-D-aspartate (NMDA) receptor activation plays a role in the transmission of nociceptive information. ${ }^{1-4}$ NMDA receptor activation does not depolarize dorsal horn neurons in the resting state but prolongs action potentials if excitatory impulses have been initiated by neurokinins or non-NMDA excitatory amino acids. ${ }^{1}$ Consequently, blockade of the NMDA receptor produces only weak or no antinociception against acute thermal or mechanical stimuli in uninjured rats ${ }^{5,6}$ but elicits antinociception in various models of persistent pain. ${ }^{2,3}$

The dissociative anesthetic agent ketamine is a noncompetitive blocker of glutamate NMDA receptors; it exhibits analgesic properties in rodents and humans and exerts a direct antinociceptive effect at the spinal lev- 
el. ${ }^{4,5}$ The molecular structure of ketamine includes a chiral center at $\mathrm{C}-2$ of the cyclohexanone ring, and hence two enantiomers of ketamine exist: $S(+)$-ketamine and $R(-)$-ketamine. The commercially available racemic ketamine preparations contain equal concentrations of the two enantiomers. The $S(t)$ enantiomer is the more potent at the NMDA receptor. ${ }^{7}$ There have been only a few published reports on the analgesic properties of the individual optical isomers of ketamine. ${ }^{4,6,8-10}$ We have found previously that the behavioral hyperalgesia associated with carrageenan-induced hind paw inflammation in rats is attenuated by the intrathecal administration of racemic ketamine and $S(+)$ ketamine, but not $R(-)$-ketamine. Neither $S(+)$-ketamine nor $R(-)$-ketamine, however, had a significant effect on results of the acute heat-pain test. ${ }^{6}$

Various drugs have been employed clinically for their spinal analgesic effects. Opioids administered through the intrathecal or epidural route are used widely to treat chronic, postoperative, and labor pain. The limitations of spinal opioids, however, are considerable. These include a variety of side-effects, such as pruritus, nausea, urinary retention, hypotension, and respiratory depression. ${ }^{11} \alpha_{2}$. Adrenoceptor-mediated spinal analgesia has been investigated extensively in animal and human studies. ${ }^{12}$ Dexmedetomidine, the active stereoisomer of medetomidine, is a new, highly selective and potent $\alpha_{2}$-adrenoceptor agonist. It recently was shown that its intrathecal administration causes an antinociceptive effect in animals, although it does have some undesired side-effects (sedation, diuresis, and mydriasis). ${ }^{13-17}$

An important technique employed to decrease sideeffects in pharmacology is the use of combinations of low doses of several agents that produce the same therapeutic effects. There are some reports on the interactions of NMDA antagonists with opioids ${ }^{3,18-23}$ or with the classic $\alpha_{2}$-adrenoceptor agonist clonidine at the spinal level..$^{22,24}$ No data are available, however, on the interactions involved in coadministration of intrathecal ketamine and dexmedetomidine, and few articles have been published on how the interactions of ketamine and morphine after intrathecal or epidural administration affect their analgesic properties. ${ }^{18,22,23}$ To the best of our knowledge, no studies have been carried out on the interactions of opiates or $\alpha_{2}$-adrenoceptor agonists with the optical isomers $S(+)$-ketamine and $R(-)$-ketamine. The purpose of the current study was to investigate the antinociceptive effects of intrathecal racemic ketamine, $R(-)$-ketamine, and $S(+)$-ketamine with low doses of morphine or dexmedetomidine on acute pain sensations, using the tail-flick test in awake rats.

\section{Methods and Materials}

\section{Intrathecal Catbeterization}

After institutional approval had been obtained from our animal care committee, 295 male Wistar rats weighing 250-350 g were studied. For spinal drug administration, rats were prepared surgically under anesthesia with ketamine and xylazine ( 87 and $13 \mathrm{mg} / \mathrm{kg}$, respectively, intraperitoneally). Because there is a possibility that prior exposure to drugs in the same class as those being studied (in this case, the same drug being studiedketamine-and the other $\alpha 2$-adrenoceptor agonist, xylazine) may be a confounding variable, we performed some sample studies ( $n=4$ or 5 per group) after barbiturate anesthesia (methohexital sodium, $40 \mathrm{mg} / \mathrm{kg}$ intraperitoneally).

An intrathecal catheter (PE-10 tubing) was inserted through a small opening in the cisterna magna and passed $8.5 \mathrm{~cm}$ caudally into the intrathecal space, as previously described. ${ }^{25}$ After surgery, the rats were housed individually, had free access to food and water, and were allowed to recover for at least 3 days before use. Rats exhibiting postoperative neurologic deficits were not used. All experiments were performed during the same period of the day (8:00 A.M. to 1:00 P.M.) to exclude diurnal variations in pharmacologic effects. The animals were assigned randomly to treatment groups ( $n=5-13$ per group), and the observer was blind to the treatment administered. Each animal was studied two or three times in an experimental series, with 6 - to 8-day intervals between studies. After experimental use, each rat was killed with an overdose of pentobarbital, and 1\% methylene blue was injected to confirm the position of the catheter and the probable spread of the injectate.

\section{Drugs}

The drugs employed were ketamine hydrochloride (Ketalar; Parke-Davis, Vienna, Austria), xylazine hydrochloride (Rompun; Bayer, Leverkusen, Germany), racemic ketamine hydrochloride, $R(-)$-ketamine hydrochloride, $S(+)$-ketamine hydrochloride (all ketamines for intrathecal administration were manufactured by ParkeDavis and were generous gifts from Gödecke, Vienna, Austria), morphine hydrochloride (Alkaloida, Tiszavasvari, Hungary), methohexital sodium (Brietal; Lilly, Budapest, Hungary), and dexmedetomidine (a generous 
gift from Orion-Farmos, Finland). Drugs were dissolved in sterile, physiologic saline. The intrathecally administered drugs were injected over $30 \mathrm{~s}$ in a volume of $5 \mu \mathrm{l}$, followed by a $10-\mu$ l flush of physiologic saline.

\section{Nociceptive Testing}

Acute nociceptive sensitivity was assessed using the tail-flick test. The reaction time in the tail-flick test was determined by immersing the lower $5 \mathrm{~cm}$ portion of the tail in hot water until a tail-withdrawal response was observed $\left(51.5^{\circ} \mathrm{C}\right.$ water, cut-off time: $\left.20 \mathrm{~s}\right)$. Baseline latencies were obtained immediately before and 10, 30, 60 , and $90 \mathrm{~min}$ after the drug injections.

\section{Experimental Paradigm}

Dose-Response Curves for Single Drugs. The first series of experiments was performed to determine the dose-response and time course for intrathecally administered morphine, dexmedetomidine, racemic ketamine, $R(-)$-ketamine, and $S(+)$-ketamine alone. On the basis of preliminary studies, four dosages each of morphine $(0.1,0.3,1$, and $3 \mu \mathrm{g})$ and dexmedetomidine $(0.3,1,3$, and $10 \mu \mathrm{g}$ ) and three dosages each of racemic ketamine and its enantiomers $(30,100$ and $300 \mu \mathrm{g})$ were examined.

Drug Interactions. The second series of experiments was performed with a fixed dose of $S(+)$-ketamine, $R(-)$-ketamine, or racemic ketamine (30 or $100 \mu \mathrm{g}$ ), with different doses of morphine $(0.03-3.0 \mu \mathrm{g})$ or dexmedetomidine $(0.1-3.0 \mu \mathrm{g})$, in order to determine the effects of racemic ketamine and its enantiomers on morphine- or dexmedetomidine-induced antinociception after ketamine-xylazine anesthesia.

Experiments after Methohexital Anesthesia. Studies with two dose levels of morphine $(0.3$ and $1 \mu \mathrm{g})$ and dexmedetomidine $(0.3$ and $3 \mu \mathrm{g})$ alone were performed. We also investigated the effects of $100 \mu \mathrm{g}$ racemic ketamine or $S(+)$-ketamine on the morphine- or dexmedetomidine-induced antinociception.

\section{Statistical Analysis}

Analgesic latencies in acute pain tests were converted to the percentage maximum possible effect using the formula:

Percentage maximum possible effect $=$ ([observed latency - baseline latency]/

[cutoff - baseline latency]) $\times 100$

Data are presented as the mean \pm SEM. Because all drugs and their combinations generally resulted in increases in the thermal withdrawal latency, with the peak effect occurring within 10-30 min, the values obtained at 10 and $30 \mathrm{~min}$ were averaged in order to obtain the value for each dosage. Dose-effect curves were constructed for each drug or drug combinations. The dosages that yielded $50 \%$ of the maximum possible effect $\left(\mathrm{ED}_{50}\right)$ and the $95 \%$ confidence intervals were calculated by linear regression. Data sets were examined by oneand two-way analyses of variance. Individual group means were compared by using the Student $t$ test. $P<$ 0.05 was considered significant.

\section{Results}

There was no significant difference in tail-flick latency between the groups $(7.0 \pm 0.10 \mathrm{~s})$ before drug administration. The tail-flick latencies of the control group did not change significantly during the period of the investigation.

\section{Single Drug Studies}

Morphine and dexmedetomidine, but not racemic ketamine and its enantiomers, resulted in dose-dependent increases in the thermal withdrawal latency, with the peak effect of either drug occurring within $30 \mathrm{~min}$ (fig. 1). The rank order of potencies, with $\mathrm{ED}_{50} \mathrm{~s}$, was morphine $1.7 \mu \mathrm{g}$ (95\% confidence interval: 1.04-2.32) followed by dexmedetomidine $4.85 \mu \mathrm{g}$ (3.96-5.79). The intrathecal injection of morphine in the dose range tested did not interfere with the gross behavior of the animals. Dexmedetomidine at higher doses (3 and 10 $\mu \mathrm{g}$ ) was associated with substantial diuresis and sedation (decreased spontaneous exploring activity, but still responsive to acoustic or tactile stimuli). Racemic ketamine and $S(+)$-ketamine in the highest dose $(300 \mu \mathrm{g})$, but not the $R(-)$ enantiomer, caused a short-lasting motor impairment. In the combination experiments, therefore, we applied only 30 or $100 \mu \mathrm{g}$ racemic ketamine, or its enantiomers, which did not cause any side effects.

\section{Double-combination Studies}

In the special case of an agent lacking effectiveness, any statistically significant decrease in the $\mathrm{ED}_{50}$ of the other, active component denotes potentiation or synergism. As such, the larger dose $(100 \mu \mathrm{g})$ of intrathecal $S(+)$-ketamine and racemic ketamine, but not $R(-)$-ketamine, synergistically enhanced the antinociception from intrathecal morphine, reducing its $\mathrm{ED}_{50}$ (table). The decrease in $\mathrm{ED}_{50}$ after the lower dose of racemic ketamine or its enantiomers was not significant, and the 

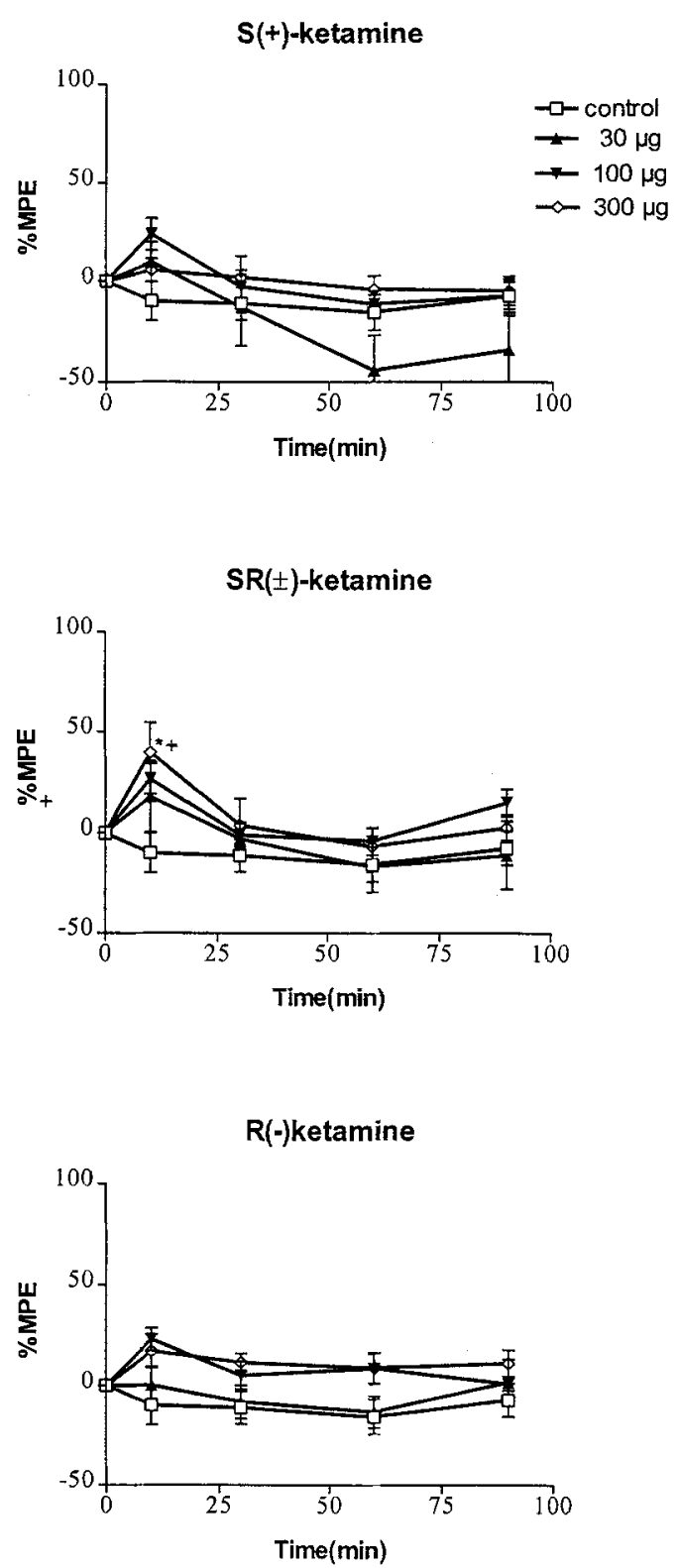

Fig. 1. Time courses of the antinociceptive effects (percentage maximum possible effect) of intrathecally administered racemic ketamine, $s(+)$-ketamine, and $R(-)$-ketamine. Each point represents the mean \pm SEM of the data from 5-14 animals. $* P<$ 0.05 versus baseline; $+P<0.05$ versus saline.

linear regression curves shifted to the left after either racemic ketamine or $S(+)$-ketamine $(100 \mu \mathrm{g})$ coadministration with morphine, but not after $R(-)$-ketamine (fig. 2).

All of the ketamine treatments significantly reduced the $\mathrm{ED}_{50}$ value of dexmedetomidine (table), although $100 \mu \mathrm{g} S(+)$-ketamine and racemic ketamine were the
Table 1. $\mathrm{ED}_{50}(\mu \mathrm{g})$ with $95 \%$ Confidence Interval (CI) for Dose-response Curve of Intrathecal Agents

\begin{tabular}{lll}
\hline Agents & $\mathrm{ED}_{50}$ & $95 \% \mathrm{Cl}$ \\
\hline Morphine & 1.66 & $1.04-2.32$ \\
$30 \mu \mathrm{g} \mathrm{S}(+)$-ketamine + morphine & 1.19 & $0.55-1.81$ \\
$100 \mu \mathrm{g} \mathrm{S}(+)$-ketamine + morphine & $0.16^{\star}$ & $0.01-0.39$ \\
$30 \mu \mathrm{g}$ Racemic-ketamine + morphine & 1.04 & $0.64-1.44$ \\
$100 \mu \mathrm{g}$ Racemic-ketamine + morphine & $0.18^{\star}$ & $0.02-0.71$ \\
$30 \mu \mathrm{g} \mathrm{R}(-)$-ketamine + morphine & 2.61 & $0.24-3.55$ \\
$100 \mu \mathrm{g} \mathrm{R}(-)$-ketamine + morphine & 2.32 & $0.55-3.35$ \\
Dexmedetomidine & 4.85 & $3.96-5.79$ \\
$30 \mu \mathrm{g} \mathrm{S}(+)$-ketamine + dexmedetomidine & $1.39^{\star}$ & $0.94-1.83$ \\
$100 \mu \mathrm{g} \mathrm{S}(+)$-ketamine + dexmedetomidine & $0.15^{\star}$ & $0.01-1.54$ \\
$30 \mu \mathrm{g}$ Racemic-ketamine + dexmedetomidine & $2.15^{\star}$ & $1.29-2.92$ \\
$100 \mu \mathrm{g}$ Racemic-ketamine + dexmedetomidine & $0.18^{\star}$ & $0.01-1.88$ \\
$30 \mu \mathrm{g} \mathrm{R}(-)$-ketamine + dexmedetomidine & $1.83^{\star}$ & $0.99-2.72$ \\
$100 \mu \mathrm{g} \mathrm{R}(-)$-ketamine + dexmedetomidine & $1.39^{\star}$ & $0.5-2.33$ \\
\hline
\end{tabular}

* Significant difference from the result of morphine or dexmedetomidine alone.

most effective in this potentiation. The linear regression curves shifted to the left after either racemic ketamine or coadministration of both enantiomers (30 or $100 \mu \mathrm{g}$ ) (fig. 2).

The time-course curves (figs, 3 and 4) revealed that smaller doses of racemic ketamine or its enantiomers did not influence the antinociceptive effects of morphine at any time point, although they potentiated the antinociceptive effects of dexmedetomidine. Racemic or $S(+)$ ketamine in the higher dose $(100 \mu \mathrm{g})$, however, not only potentiated but also prolonged the antinociceptive effect of either morphine or dexmedetomidine. Moreover, $S(+)$-ketamine $(100 \mu \mathrm{g})$ with $0.3 \mu \mathrm{g}$ morphine or dexmedetomidine caused a longer antinociception than the racemic ketamine combinations (figs. 3 and 4). In no other cases were any differences observed between racemic ketamine and $S(+)$-ketamine $(100 \mu \mathrm{g})$. Animals receiving the combinations exhibited no severe sideeffects or unusual behavior.

\section{Results after Metbobexital Anesthesia}

The analysis of the time-course curves after methohexital anesthesia revealed that, similar to ketamine-xylazine anesthesia, morphine and dexmedetomidine cause dosedependent antinociception, and both racemic ketamine and $S(+)$-ketamine potentiated this effect (fig. 5).

\section{Discussion}

This is the first study of the antinociceptive properties of coapplied ketamine and dexmedetomidine and ket- 
morphine $+30 \mu g$ ketamine

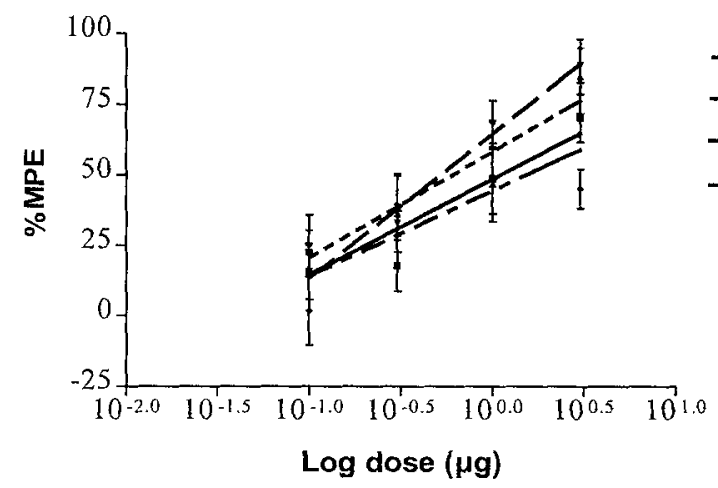

morphine $+100 \mu g$ ketamine

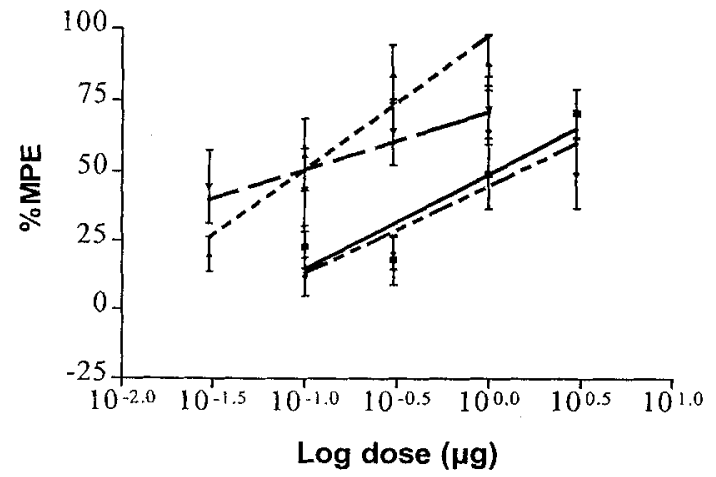

dexmedetomidine + $30 \mu \mathrm{g}$ ketamine
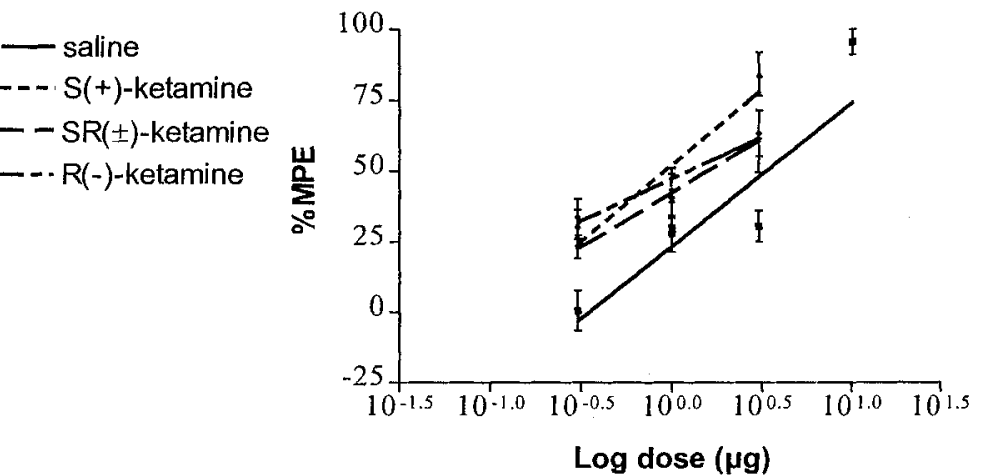

dexmedetomidine + $100 \mu \mathrm{g}$ ketamine

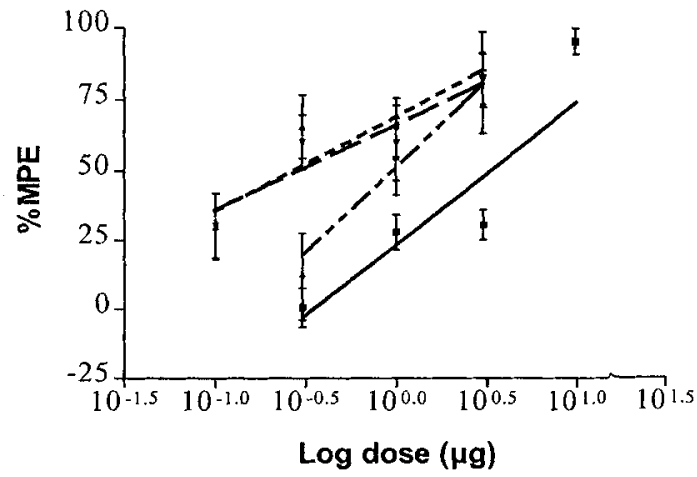

Fig. 2. Log dose-response curves for the antinociceptive effects (percentage maximum possible effect) of intrathecally administered morphine (left) or dexmedetomidine (right), alone or with the addition of 30 or $100 \mu g$ racemic ketamine, $R(-)$-ketamine, or $s(+)$-ketamine. Each point represents the mean \pm SEM of the data from 5-14 animals.

amine and morphine in which the effectiveness of $S(+)$ ketamine, $R(-)$-ketamine, and racemic ketamine administered intrathecally to rats were compared using an acute heat-pain test. We observed synergistic interactions between the higher dose of racemic ketamine or $S(+)$-ketamine and morphine or dexmedetomidine, and this potentiation was independent of the anesthetic drug applied. Coadministration of a low dose of morphine or dexmedetomidine $(0.3 \mu \mathrm{g})$ with $S(+)$-ketamine $(100$ $\mu \mathrm{g}$ ), which in itself induced no changes in pain sensation or behavior, caused a significant long-lasting antincociception, without any side-effects. Ketamine was more effective after coadministration with dexmedetomidine, and this potentiation could be observed after $R(-)$-ketamine coadministration as well.

The dissociative anesthetic agent ketamine is a noncompetitive blocker of glutamate NMDA receptors, acting on the phencyclidine site; it exhibits analgesic prop- erties in rodents and humans, ${ }^{4,5,9}$ It binds to opioid and acetylcholine receptors also, but the affinity of ketamine for these receptors is lower than that for the NMDA channel, which suggests that the interaction is not of major clinical importance. ${ }^{4,8}$ The intrathecal administration of ketamine produces only weak or no analgesic effects against acute pain, such as that in the tail-flick test, ${ }^{6}$ although ketamine reduces the hyperalgesic effect of a hind paw carragenan injection ${ }^{2,6}$ and of nerve injury. ${ }^{26,27}$

Various studies already have demonstrated the beneficial antinociceptive effect of opioids and NMDA receptor antagonists coadministrated by either a systemic ${ }^{28,29}$ or an intrathecal route. ${ }^{18,20,30-33}$ Powerful synergism arises from combinations of threshold doses of morphine with low doses of NMDA antagonists, ${ }^{30-33}$ in agreement with our results. Other studies, ${ }^{18-20}$ however, failed to observe any potentiation of NMDA recep- 

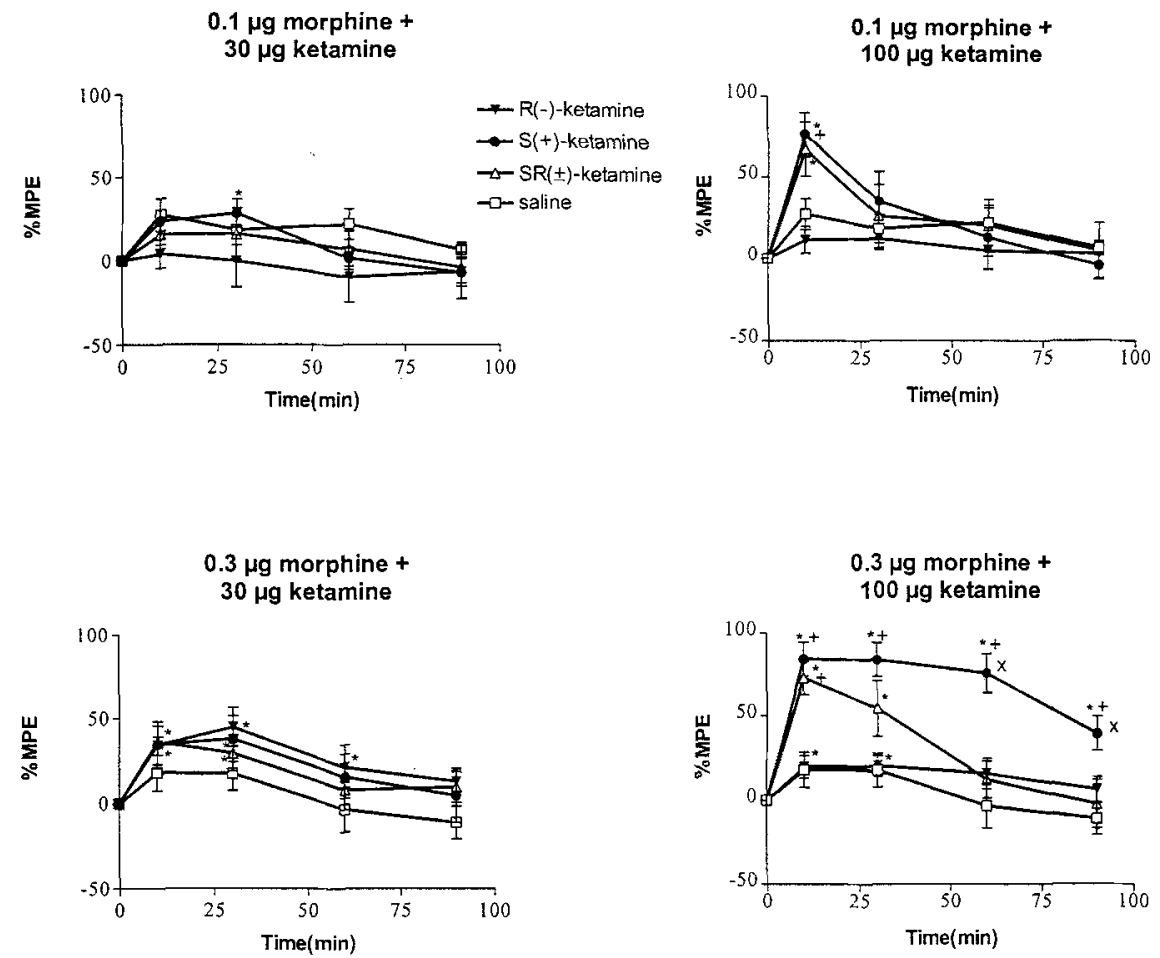

Fig. 3. Time course of antinociceptive effects (percentage maximum possible effect) for various mixtures of 30 or $100 \mu \mathrm{g}$ racemic ketamine, $R(-)$-ketamine, or $S(+)$-ketamine with morphine. Each point represents the mean \pm SEM of the data from 5-14 animals. ${ }^{P} P<0.05$ versus baseline; $+P<0.05$ versus saline; $\mathrm{x} P<$ 0.05 versus racemic ketamine-morphine treatment.
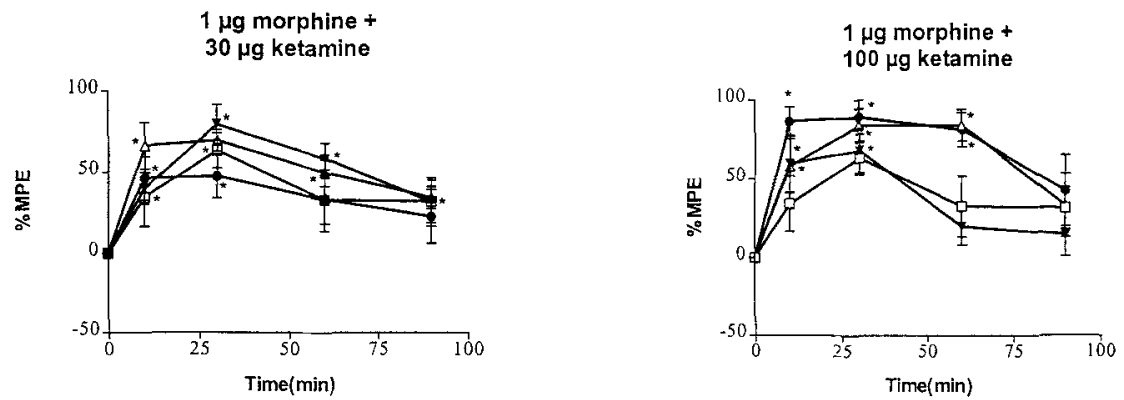

tor antagonists on morphine-induced antinociception in acute pain tests. This discrepancy may be a result of the different methods of drug administration or differences in the applied dose or the applied pain tests.

Many previous studies have indicated that the intrathecal administration of $\alpha_{2}$-adrenoceptor agonists produces analgesia in animals and humans. ${ }^{12-14,34,35}$ Intrathecal $\alpha_{2}$-adrenergic agonists mimic the effects of endogenous norepinephrine and may produce antinociception by decreasing the release of glutamate from primary afferent nerve terminals, ${ }^{36}$ thereby suppressing the activity of wide dynamic range neurons evoked by noxious stimu- 1i. ${ }^{37}$ The systemic coadministration of an $\alpha_{2}$-adrenoceptor agonist (i.e., clonidine, xylazine, or medetomidine) and an NMDA antagonist (especially ketamine) in animal studies provides adequate analgesia, muscle relaxation, and complete immobilization; this is therefore a widely used combination in veterinary anesthesia. ${ }^{38}$ Behavioral and electrophysiologic studies in rodents indicated the importance of adrenoceptors in modulating the behavior and excitation induced by the intrathecal administration of NMDA. ${ }^{39,40}$ Only a few data are available on the interactions between these drugs after intrathecal administration; for example, Lee and Yaksh ${ }^{24}$ have shown 
Fig. 4. Time course of antinociceptive effects (percentage maximum possible effect) for various mixtures of 30 or $100 \mu \mathrm{g}$ racemic ketamine, $R(-)$-ketamine, or $s(+)$-ketamine with dexmedetomidine. Each point represents the mean \pm SEM of the data from $5-14$ animals. ${ }^{*} P<0.05$ versus baseline; $+P<0.05$ versus saline; $\mathrm{x} P<0.05$ versus racemic ketaminedexmedetomidine treatment.
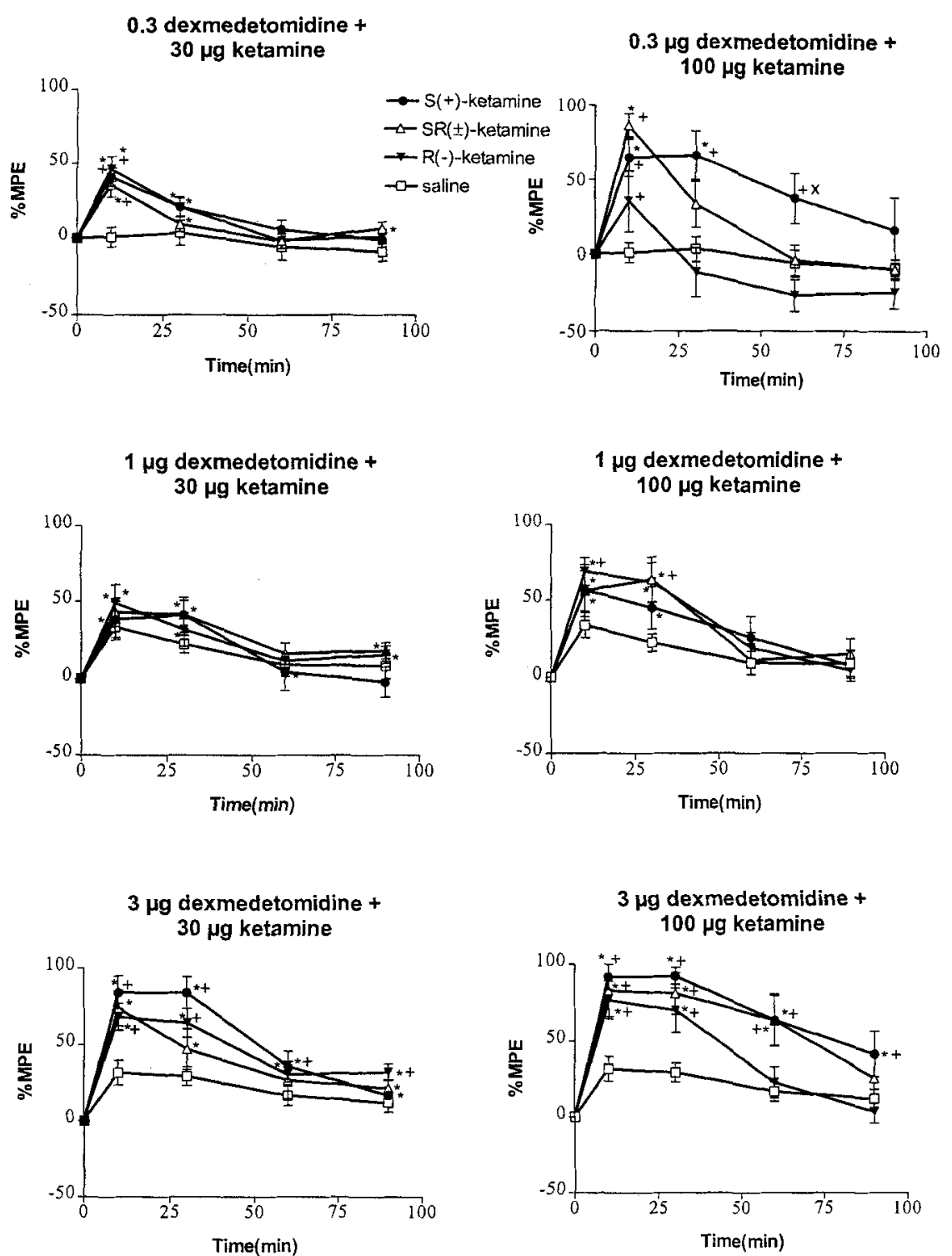

that the intrathecal coadministration of clonidine and MK-801 results in a dose-dependent increase in the mechanical pain threshold in a peripheral neuropathic pain rat model.

There are several possibilities for synergistic interaction between ketamine and morphine or dexmedetomidine. Because opioid, glutamate, and $\alpha_{2}$-adrenergic receptors are abundant in the spinal cord, ${ }^{41}$ coactivation and antagonisms of these receptors could have a beneficial effect on the inhibition of pain sensation at low dosages, which cause minimal side-effects. There are differences in mechanism of action between ketamine and morphine or dexmedetomidine. Ketamine decreases the activation of dorsal horn neurons, by inhibiting the ionotropic glutamate receptor opening. ${ }^{7}$ A major mechanism of spinal opioid and $\alpha_{2}$-adrenoceptor agonist analgesia is the inhibition of transmitter release from the C-fiber primary afferent terminal, although they have inhibitory effects on both interneurons and projecting neurons. ${ }^{36,42-44}$ Presynaptic action of these drugs contrasts with the postsynaptic location of the NMDA receptor. The dual actions at both pre-and postsynaptic sites allow the possibility of synergy. It is also possible that the augmented activity results from a decreased 

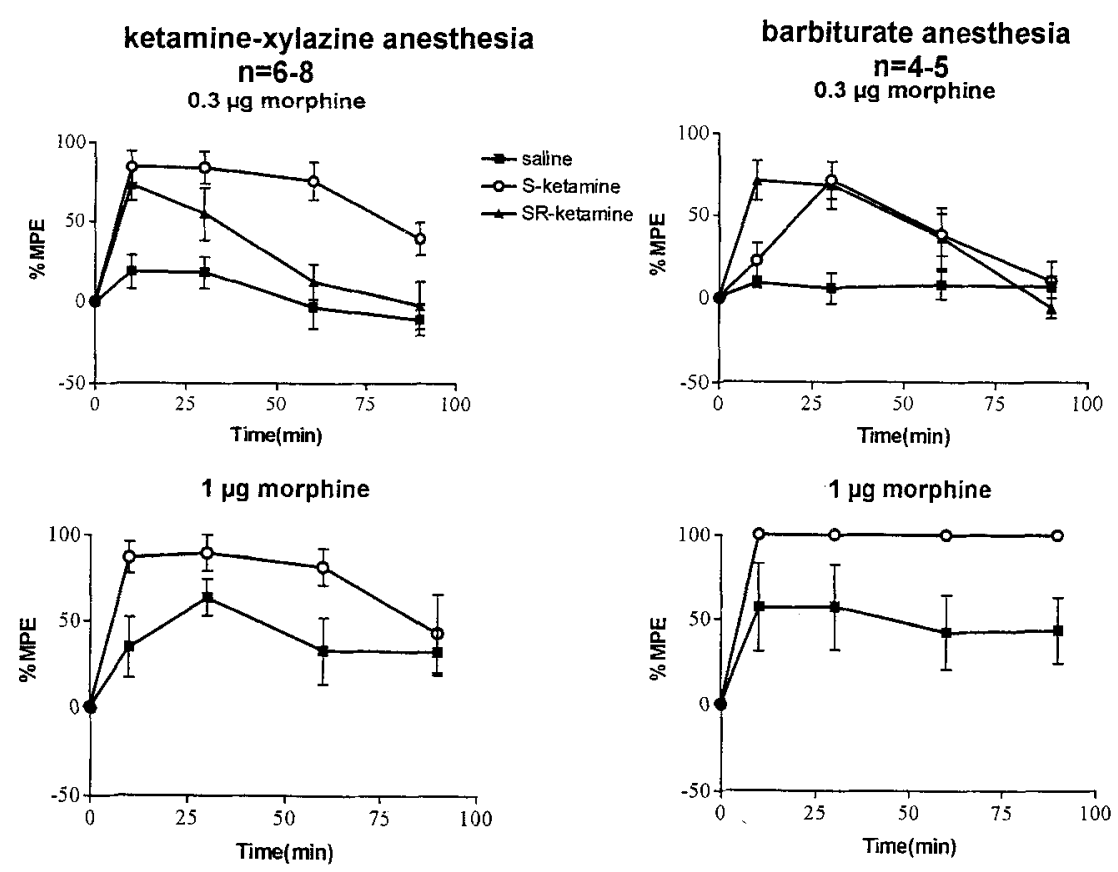

Fig. 5. Time course of antinociceptive effects (percentage maximum possible effect) for mixtures of $100 \mu \mathrm{g}$ racemic ketamine or $S(+)$-ketamine with morphine or dexmedetomidine using different anesthetic protocols. Each point represents

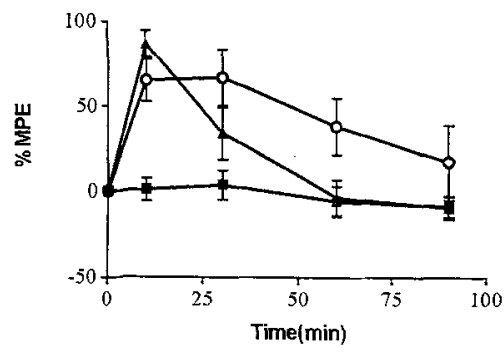

$0.3 \mu \mathrm{g}$ dexmedetomidine

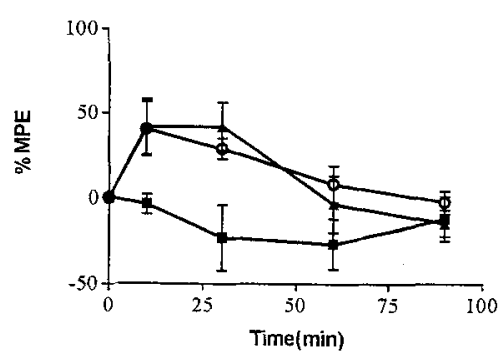
the mean \pm SEM of the data.

$3 \mu \mathrm{g}$ dexmedetomidine
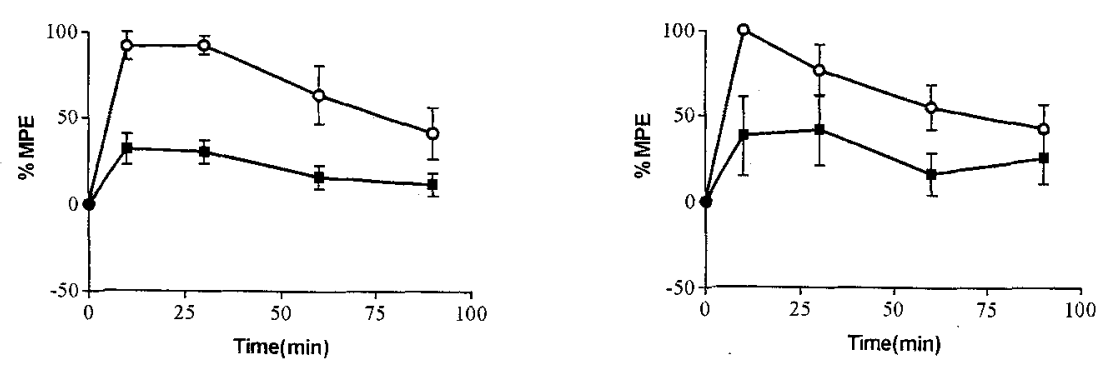

clearance of drugs from the intrathecal space, because the duration of action of the combinations was longer than that of morphine or dexmedetomidine alone.

The potential advantages of using a pure enantiomer rather than a racemate include a less complex and more selective pharmacodynamic profile, a higher therapeutic index, and less complex pharmacokinetics, drug interactions, and concentration-response relations. For finan- cial reasons, pure isomers so far have been used only for research purposes, but the wide-ranging clinical use of pure isomers now is financially feasible, because of new production techniques. ${ }^{45}$ Marietta et $a l .{ }^{10}$ reported differences in the pharmacologic potencies of the optical isomers of ketamine in rats. Human studies revealed differences in anesthetic potency, intraoperative effects, postoperative analgesia, and side-effects of the two en- 
antiomers. ${ }^{46}$ The $S(+)$ enantiomer has four times the potency of the $R(-)$ enantiomer of ketamine as an anesthetic, and it may have significant clinical advantages in comparison with the racemic drug, such as fewer side-effects. Differences also exist in the pharmacokinetics of the ketamine enantiomers. If they are administered individually, the plasma clearance of $S(+)$-ketamine is greater than that of the $R(-)$ enantiomer. Kharasch and Labroo ${ }^{47}$ have demonstrated a relative enantiomeric selectivity in the human metabolism. Not all of the effects of ketamine, however, are stereoselective. ${ }^{\mathbf{4}, 48}$ We previously examined the effects of the two isomers of ketamine on acute and inflammatory pain sensations in rats. ${ }^{6}$ We found that the behavioral hyperalgesia associated with carrageenan-induced hind paw inflammation in rats is attenuated by the intrathecal administration of racemic ketamine or $S(+)$-ketamine, but not $R(-)$-ketamine; neither $S(+)$-ketamine nor $R(-)$-ketamine had a significant effect on results of the tail-flick test.

Racemic ketamine has been administered epidurally to humans for pain relief without side-effects such as respiratory depression, urinary retention, or pruritus that frequently are observed after epidural opioids. ${ }^{49}$ The neuraxial use of NMDA receptor antagonists has raised the question of potential toxicity, ${ }^{50,51}$ although neurologic lesions have not been reported after intrathecal administration of racemic ketamine in human studies. ${ }^{49}$ In a study by Kristensen et al., ${ }^{51}$ the chronic intrathecal administration of pharmacologically active doses of different NMDA receptor antagonists in rats did not produce neurotoxic effects in the spinal cord. There is now a clinical report, however, of neurotoxiciy from intrathecal ketamine with benzathonium chloride as a preservative. ${ }^{52}$ Preservatives (benzathonium chloride or chlorobutanol) used in ketamine solution in some cases were thought to cause neurologic damage in animals. The isomers of ketamine do not themselves induce spinal cord lesions, but the preservative chlorobutanol leads to significant spinal cord damage in rabbits, ${ }^{50}$ and benzethonium chloride is toxic in swine, ${ }^{53}$ but not in primates. ${ }^{54}$ In one study that used preservative-free ketamine, vacuolation of the dorsal root ganglia occurred in three rats that suddenly died $(500 \mu \mathrm{g}){ }^{5}$

The fact that $S(+)$-ketamine had a higher efficacy than racemic ketamine agrees only with some earlier results. $^{6,55}$ There might be several explanations for this. Pharmacokinetically, we presume that in the racemic combination, $R(-)$-ketamine decreases the elimination of $S(+)$-ketamine, as suggested by Kharasch and Labroo. ${ }^{47}$ Further, it has been shown that $R(-)$-ketamine also binds to the NMDA receptors, but with lower affinity, ${ }^{7}$ and our previous results suggested that $R(-)$-ketamine has a tendency to cause significant antinociception. ${ }^{6}$ The fact that both enantiomers of ketamine potentiated the antinociceptive effects of dexmedetomidine is in line with these results.

One approach to improve analgesia is to combine small doses of analgesics that interact synergistically to produce analgesia without increasing the side-effects. There is a risk of delayed hallucinations from intrathecal racemic ketamine, as Kristensen et al. ${ }^{56}$ described for another NMDA receptor antagonist administered intrathecally to humans, but there were no previous human data on the intrathecal administration of $S(+)$-ketamine. The subjective mood was judged to be significantly better, and no unpleasant dreams were reported after systemic $S(+)$-ketamine compared with the group treated with racemic ketamine. ${ }^{46}$ Although these side effects cannot be predicted from rat studies, we did observe motor impairment at the highest dose $(300 \mu \mathrm{g})$. Similarly, side-effects also were observed often in response to high doses of morphine and dexmedetomidine alone, but not in combination with ketamine, at much lower doses. Finally, because the commercially available $S(+)$ ketamine preparation does not contain preservatives, and toxicologic assessments have demonstrated that it is innocuous in two animal species, ${ }^{50,53}$ it appears that it may be appropriate to administer $S(+)$-ketamine intrathecally to humans in small doses.

The intrathecal administration of racemic ketamine and $S(+)$-ketamine alone caused no antinociception to a thermal stimulus in rats, but significantly potentiated and prolonged morphine or dexmedetomidine-induced antinociception. $R(-)$-ketamine potentiated the antinociceptive effect of dexmedetomidine, but not that of morphine. Our data provide additional evidence concerning the notion that the pure enantiomer $S(+)$-ketamine can be a potent component of combined antinociceptive therapy. These findings may provide a rationale for combining such drugs for improved human postoperative pain treatment in the future.

The authors thank Dr. James Eisenach, Department of Anesthesiology, Bowman Gray Hospital, Winston-Salem, North Carolina, for his critique of the manuscript; Gerold Reinitzer, Gödecke/Parke Davis LTD, Vienna, Austria, for providing the ketamine enantiomers produced by Parke-Davis; and Orion-Farmos, Turbu, Finland, for dexmedetomidine. 


\section{References}

1. Dickenson AH: Spinal cord pharmacology of pain. Br J Anaesth 1995; 75:193-200

2. Ren K, Williams GM, Hylden JLK, Ruda MA, Dubner R: The intrathecal administration of excitatory amino acid receptor antagonists selectively attenuated carrageenan-induced behavioral hyperalgesia in rats. Eur J Pharmacol 1992; 219:235-23

3. Yamamoto $T$, Shimoyama N, Mizuguchi T: The effects of morphine, MK-801, an NMDA antagonist, and CP-96,345, an NK-1 antagonist, on the hyperesthesia evoked by carageenan injection in the rat paw. ANESTHESIOLOGY 1993; 78:124-33

4. Kohrs R, Duireux ME: Ketamine: Teaching an old drug new tricks. Anesth Analg 1999; 87:1186-93

5. Ahuja BR: Analgesic effect of intrathecal ketamine in rats. Br J Anaesth 1983; 55:991-5

6. Klimscha W, Horváth G, Szikszay M, Dobos I, Benedek G: Antinociceptive effect of the $S(+)$-enantiomer of ketamine on carrageenan hyperalgesia after intrathecal administration in rat. Anesth Analg 1998; 86:561-5

7. Hirota K, Lambert DG: Ketamine: Its mechanism(s) of action and unusual clinical uses. Br J Anaesth 1996; 77:441-4

8. Reich DL, Silvay G: Ketamine: An update on the first twenty-five years of clinical experience. Can J Anaesth 1989; 36:186-97

9. Geisslinger G, Hering W, Thomann P, Knoll R, Kamp H-D, Brune $K$ : Pharmacokinetics and pharmacodynamics of ketamine enantiomers in surgical patients using a stereoselective analytical method. $\mathrm{Br} \mathrm{J}$ Anaesth 1993; 70:666-71

10. Marietta MP, Way W, Castagnoli NJr, Trevor AJ: On the pharmacology of the ketamine enantiomorphs in the rat. J Pharmacol Exp Ther 1977; 202:157-65

11. Cousins MJ, Mather LE: Intrathecal and epidural administration of opioids. ANESTHESIOLOGY 1984; 61:276-310

12. Eisenach JC, De Kock M, Klimscha W: $\alpha_{2}$-adrenergic agonists for regional anesthesia A clinical review of clonidine (1984-1995). ANESTHESIOLOGY 1996; 85:655-74

13. Horváth G, Kovács M, Szikszay M, Benedek G: Mydriatic and antinociceptive effects of intrathecal dexmedetomidine in conscious rats. Eur J Pharmacol 1994; 253:61-6

14. Aantaa R, Kallio A, Virtanen R: Dexmedetomidine, a novel $\alpha_{2^{-}}$ adrenergic agonist: $\mathbf{A}$ review of its pharmacodynamic characteristics. Drugs Future 1993; 18:49-56

15. Klimscha W, Tong C, Eisenach JC: Intrathecal $\alpha_{2}$-adrenergic agonists stimulate acetylcholine and norepinephrine release from the spinal cord dorsal horn in sheep. ANesthesiology 1997, 87:110-6

16. Sullivan AF, Kalso EA, McQuay HJ, Dickenson AH: The antinociceptive actions of dexmedetomidine on dorsal horn neuronal responses in the anaesthetized rat. Eur J Pharmacol 1992; 215:127-33

17. Takano Y, Yaksh TL: Characterization of the pharmacology of intrathecally administered alpha-2 agonists and antagonists in rats. J Pharmacol Exp Ther 1992; 257:764-72

18. Srivastava RK, Gombar KK, Kaur AH, Khosla P: Attenuation of morphine-induced antinociception by L-glutamic acid at the spinal site in rats. Can J Anaesth 1995, 42:541-6

19. Nishizawa M, Yaksh TL, Weber E: Effects of intrathecal NMDA and non-NMDA antagonists on acute thermal nociception and their interaction with morphine. ANESTHESIOLOGY 1998, 89:715-22

20. Ossipov MH, Lopez Y, Nichols ML, Bian D, Porreca F: The loss of antinociceptive efficacy of spinal morphine in rats with nerve ligation injury is prevented by reducing spinal afferent drive. Neurosci Lett 1995; 199:87-90

21. Yamamoto T, Yaksh TL: Studies on the spinal interaction of morphine and the NMDA antagonist MK-801 on the hyperesthesia observed in a rat model of sciatic mononeuropathy. Neurosci Lett 1992; $135: 67-70$

22. Muller A, Lemos D: Cancer pain: Beneficial effect of ketamine addition to spinal administration of morphine-clonidine-lidocaine mixture. Ann Fr Anesth Reanim 1996; 15:271-6

23. Choe H, Choi Y-S, Kim Y-H, Ko S-H, Choi H-G, Han Y-J, Song H-S: Epidural morphine plus ketamine for upper abdominal surgery: Improved analgesia from preincisional versus postincisional administration. Anesth Analg 1997; 84:560-3

24. Lee Y-W, Yaksh TL: Analysis of drug interaction between intrathecal clonidine and MK-801 in peripheral neuropathic pain rat model. ANESTHESIOLOGY 1995; 82:741-8

25. Yaksh TL, Rudy TA: Chronic catheterization of the spinal subarachnoid space. Physiol Behav 1976; 17:1031-6

26. Mao J, Price DD, Hayes RL, Lu J, Mayer DJ, Frenk H: Intrathecal treatment with dextrorphan or ketamine potently reduces pain-related behaviors in a rat model of peripheral mononeuropathy. Brain Res 1993; 605:164-8

27. Yamamoto T, Yaksh TL: Spinal pharmacology of thermal hyperesthesia induced by constriction injury of sciatic nerve. Excitatory amino acid antagonists. Pain 1992, 49:121-8

28. Advokat C, Rhein FQ: Potentiation of morphine-induced antinociception in acute spinal rats by the NMDA antagonist dextrorphan. Brain Res 1995; 699:157-60

29. Honoré P, Chapman V, Buritova J, Besson J-M: Concomitant administration of morphine and an N-methyl-D-aspartate receptor antagonist profoundly reduces inflammatory evoked spinal c-Fos expression. ANESTHESIOLOGY 1996; 85:150-60

30. Dickenson AH: NMDA receptor antagonists: interactions with opioids. Acta Anaesthesiol Scand 1997; 41:112-5

31. Wiesenfeld-Hallin Z: Combined opioid-NMDA antagonist therapies. Drugs 1998; 55:1-4

32. Chapman V, Dickenson AH: The combination of NMDA antagonism and morphine produces profound antinociception in the rat dorsal horn. Brain Res 1992; 573:321-3

33. Wong C-S, Cherng C-H, Luk H-N, Ho S-T, Tung C-S: Effects of NMDA receptor antagonists on inhibition of morphine tolerance in rats: Binding at $\mu$-opioid receptors. Eur J Pharmacol 1996; 297:27-33

34. Fisher BC, Zornow MH, Yaksh TL: Antinociceptive effects of intrathecal dexmedetomidine in rats. Anesth Analg 1990; 70:\$106

35. Klimscha W, Chiari A, Krafft P, Plattner O, Taslimi R, Mayer N, Weinstabl C, Schneider B, Zimpfer M: Hemodynamic and analgesic effects of clonidine added repetitively to continuous epidural and spinal blocks. Anesth Analg 1995; 80:1-6

36. Ueda M, Oyama T, Kuraishi Y, Akaike A, Satoh M: Alpha2adrenoceptor-mediated inhibition of capsaicin-evoked release of glutamate from rat spinal dorsal horn slices. Neurosci Lett 1995; 188:137-9

37. Murata K, Nakagawa I, Kumeta Y, Kitahata LM, Collins JG: Intrathecal clonidine suppresses noxiously evoked activity of spinal wide dynamic range neurons in cats. Anesth Analg 1989; 69:185-91

38. Maze M, Tranquilli W: Alpha-2 adrenoceptor agonists: Defining the role in clinical anesthesia. ANESTHESIOLOGY 1991; 74:581- 605

39. Aanonsen LM, Wilcox GL: Nociceptive action of excitatory amino acids in the mouse: Effects of spinally administered opioids 
phencyclidine and sigma agonists. J Pharmacol Exp Ther 1987; 243: 9-19

40. Zhang M-K, Wang X-M, Peterson AM, Chen W-Y, Mokha SS: $\alpha_{z}$-Adrenoceptors modulate NMDA-evoked responses of neurons in superficial and deeper dorsal horn of the medulla. J Neurophysiol $1998 ; 80: 2210-4$

41. Coggeshall RE, Carlton SM: Receptor localization in the mammalian dorsal horn and primary afferent neurons. Brain Res Rev 1997; 24:28-66

42. Besse D, Lombard M-C, Zajac J-M, Roques BP, Besson J-M: Preand postsynaptic location of mu, delta and kappa opioid receptors in the superficial layers of the dorsal horn of the rat spinal cord. Brain Res $1990 ; 521: 15-22$

43. Kuraishi Y, Hirota N, Sugimoto M, Satoh M, Takagi H: Effects of morphine on noxious stimuli-induced release of substance $P$ from rabbit dorsal horn in vivo. Life Sci 1983; 33:693-696

44. Kamisaki Y, Hamada T, Maeda K, Ishimura M, Itoh T: Presynaptic $\alpha_{2}$ adrenoceptors inhibit glutamate release from rat spinal cord synaptosomes. J Neurochem 1993; 60:522-526

45. Graf BM, Martin E: Stereoisomere in der Anästhesie Teoretishe Grundlagen und klinische Bedeutung. Anaesthesist 1998; 47:172-83

46. White PF, Schüttler J, Shafer A, Stanski DR, Horai Y, Trevor AJ: Comparative pharmacology of the ketamine isomers. $\mathrm{Br} \mathbf{J}$ Anaesth $1985 ; 57: 197-203$

47. Kharasch ED, Labroo R: Metabolism of ketamine stereoisomers by human liver microsomes. ANESTHESIOLOGY 1992; 77:1201-7

48. Sekino N, Endou M, Hajiri E, Okumura F: Nonstereospecific actions of ketamine isomers on the force of contraction, spontaneous beating rate, and $\mathrm{Ca} 2+$ current in the guinea pig heart. Anesth Analg $1996 ; 83: 75-80$

49. Ravat F, Dorne R, Baechie JP, Beaulaton A, Lenoir B, Palmier B: Epidural ketamine or morphine for postoperative analgesia. ANESTHESTOLOGY $1987 ; 66: 819-22$

50. Malinovsky J-M, Lepage J-Y, Cozian A, Mussini J-M, Pinaudt M, Souron R: Is ketamine or its preservative responsible for neurotoxicity in the rabbit? ANESTHESIOLOGY $1993 ; 78: 109-5$

51. Kristensen JD, Post C, Gordh T], Svensson BA: Spinal cord morphology and antinociception after chronic intrathecal administration of excitatory amino acid antagonists in the rat. Pain 1993; 54 309-16

52. Karpinski N, Dunn J, Hansen L, Masliah E: Subpial vacuolar myelopathy after intrathecal ketamine: report of a case. Pain 1997; 73:103-5

53. Errando CL, Sifre C, Moliner S, Valia JC, Gimeno O, Minguez A, Boils P: Subarachnoid ketamine in swine: Pathological findings after repeated doses: Acute toxicity study. Reg Anesth Pain Med 1999; 24:146-52

54. Brock-Utne JG, Mankowitz E, Kallichurum S, Dawning JW: Effects of intrathecal saline and ketamine with and without preservative on the spinal nerve roots of monkeys. S Afr Med J 1982; 61:360-1

55. Hancock PJ, Stamford JA: Stereospecific effects of ketamine on dopamine efflux and uptake in the rat nucleus accumbens. $\mathrm{Br} J$ Anaesth 1999; 82:603-8

56. Kristensen JD, Svensson B, Gordh TJr: The NMDA-receptor antagonist CPP abolishes neurogenic "wind-up pain" after intrathecal administration in humans. Pain 1992; 51:249-53 